\title{
Ibuprofen treatment modifies cortical sources of EEG rhythms in mild Alzheimer's disease
}

\author{
Claudio Babiloni ${ }^{\mathrm{a}, \mathrm{b}, *}$, Giovanni B. Frisoni ${ }^{\mathrm{c}}$, Claudio Del Percio ${ }^{\mathrm{c}}$, Orazio Zanetti ${ }^{\mathrm{c}}$, Cristina Bonomini ${ }^{\mathrm{c}}$, \\ Emanuele Cassetta ${ }^{d}$, Patrizio Pasqualetti ${ }^{\text {b,d }}$, Carlo Miniussi ${ }^{c, e}$, Mario De Rosas ${ }^{a}$, Anna Valenzano ${ }^{a}$, \\ Giuseppe Cibelli ${ }^{\text {a }}$, Fabrizio Eusebi ${ }^{\text {f,g }}$, Paolo M. Rossini ${ }^{\text {b,d,h }}$ \\ a Department of Biomedical Sciences, University of Foggia, Viale Pinto 7, Foggia I-71100, Italy \\ ${ }^{\mathrm{b}}$ Casa di Cura San Raffaele Cassino, Via G. Di Biasio 1, Cassino (FR), Italy \\ ' IRCCS Fatebenefratelli “San Giovanni di Dio", Brescia, Italy \\ ${ }^{\mathrm{d}}$ Associazione Fatebenefratelli per la ricerca (AFaR), Hospital S. Giovanni Calibita, Rome, Italy \\ e Department of Neuroscience, University of Brescia, Brescia, Italy \\ ${ }^{\mathrm{f}}$ Dipartimento di Fisiologia e Farmacologia, Università “Sapienza”, Roma, Italy \\ ${ }^{\mathrm{g}}$ IRCCS Neuromed, Via Atinense 18, Pozzilli (Isernia), Italy \\ ${ }^{\text {h }}$ Clinica Neurologica, Campus Biomedico University, Rome, Italy
}

\section{A R T I C L E I N F O}

Article history:

Accepted 3 February 2009

\section{Keywords:}

Mild Alzheimer's disease (mild AD) Ibuprofen

Electroencephalography (EEG)

Low-resolution brain electromagnetic

tomography (LORETA)

\begin{abstract}
A B S T R A C T
Objective: Non-steroidal anti-inflammatory drugs such as ibuprofen have a protective role on risk of Alzheimer's disease (AD). Here we evaluated the hypothesis that long-term ibuprofen treatment affects cortical sources of resting electroencephalographic (EEG) rhythms in mild AD patients.

Methods: Twenty-three AD patients (13 treated AD IBUPROFEN; 10 untreated AD PLACEBO) were enrolled. Resting EEG data were recorded before and 1 year after the ibuprofen/placebo treatment. EEG rhythms were delta $(2-4 \mathrm{~Hz})$, theta $(4-8 \mathrm{~Hz})$, alpha $1(8-10.5 \mathrm{~Hz})$, alpha $2(10.5-13 \mathrm{~Hz})$, beta $1(13-$ $20 \mathrm{~Hz})$, and beta $2(20-30 \mathrm{~Hz})$. LORETA was used for EEG source analysis.

Results: In the AD PLACEBO group, amplitude of delta sources was globally greater at follow-up than baseline. Instead, amplitude of delta sources remained stable or decreased in the majority of the AD IBUPROFEN patients. Clinical (CDR) but not global cognitive status (MMSE) reflected EEG results.

Conclusions: These results suggest that in mild AD patients, a long-term ibuprofen treatment slightly slows down the progressive increment of delta rhythms as a sign of contrast against the neurodegenerative processes.

Significance: They motivate future investigations with larger population and extended neuropsychological testing, to study the relationships among ibuprofen treatment, delta cortical sources, and higher order functions.

(c) 2009 International Federation of Clinical Neurophysiology. Published by Elsevier Ireland Ltd. All rights
\end{abstract} reserved.

\section{Introduction}

Quantitative analysis of electroencephalographic (EEG) rhythms in awakening subjects at rest (eyes closed) is a low-cost, easy to perform, and widely available neurophysiological approach to the study of Alzheimer disease (AD; Maurer and Dierks, 1992; Szelies et al., 1992; Leuchter et al., 1993; Schreiter-Gasser et al., 1993; see Rossini et al., 2007 for a review). When compared to normal elderly subjects (Nold), AD patients were characterized by excessive delta $(0-4 \mathrm{~Hz})$ and theta $(4-7 \mathrm{~Hz})$ rhythms, and a significant decre-

\footnotetext{
* Corresponding author. Address: Department of Biomedical Sciences, University of Foggia, Viale Pinto 7, Foggia I-71100, Italy. Tel.: +39 0881 713276; fax: +39 0881 711716.

E-mail address: c.babiloni@unifg.it (C. Babiloni).
}

ment of posterior alpha rhythms (8-12 Hz; Dierks et al., 1993, 2000; Huang et al., 2000; Ponomareva et al., 2003; Jeong, 2004; Babiloni et al., 2004 Babiloni et al., 2006a,b,c,d,e,f, Babiloni et al., 2007a,b,c, 2008). These EEG abnormalities were associated with altered regional cerebral blood flow ( $\mathrm{rCBF}$ )/metabolism and with neuropsychological battery, including those for global cognitive function as evaluated by mini mental state examination (MMSE; Sloan et al., 1995; Rodriguez et al., 1998, 1999; Jeong, 2004).

Resting EEG rhythms in AD patients are sensitive to the effects of symptomatic pharmacological treatment with acetylcholinesterase inhibitors (AChEI). In particular, short-term AChEI treatment has induced decrement of theta power (Brassen and Adler, 2003), increment of alpha power (Onofrj et al., 2003) as well as decrement of alpha and delta power $(0-3 \mathrm{~Hz})$ (Reeves et al., 2002). Instead, long-term AChEI treatment has induced decrement of theta power 
(Kogan et al., 2001) and increment of alpha/theta power ratio, especially in frontal regions (Rodriguez et al., 2002). Finally, power of posterior alpha sources has been found to be modulated by longterm cholinergic therapy (Donepezil) in AD subjects (Babiloni et al., 2006f). Those results confirmed the implication of cholinergic systems in the neurodegenerative processes at the basis of AD.

The above findings suggest that resting EEG rhythms might be used as markers of disease progression and surrogate outcome in clinical trials. We have tested this hypothesis in a 1-year randomized clinical trial of ibuprofen, an NSAID with antiamyloidogenic activity. The rationale for the trial lies in $\mathrm{AD}$ neurodegenerative processes being affected by chronic inflammatory response in the brain tissue as demonstrated by the presence of activated microglia, proinflammatory mediators, and complement factors around senile plaques (Neuroinflammation Working Group 2000, Akiyama et al., 2000). This hypothesis is corroborated by several epidemiological investigations suggesting a protective role of non-steroidal anti-inflammatory drugs (NSAIDs) such as ibuprofen on the risk of developing AD (Andersen et al., 1995; Anthony et al., 2000; Broe et al., 2000; Stewart et al., 1997; In 't Veld et al., 1998; Zandi et al., 2002). Even if the consensus has not been universal (Henderson et al., 1997; Beard et al., 1989; In 't Veld et al., 1998) because of great differences in study design, the bulk of evidence seems to be in favor of a protective role of NSAIDs on AD risk, with a greater risk reduction with longer use of the anti-inflammatory compounds prior to the onset of AD symptoms (Zandi et al., 2002). The mechanism by which NSAIDs might operate in reducing AD risk is unclear. A small number of NSAIDs, among which are ibuprofen, sulindac sulfite and indomethacin, have been found to exert an antiamyloidogenic activity in vivo and in vitro, a mechanism at least in part independent of COX inhibition (Lim et al., 2000; Weggen et al., 2001). However, clinical trials trying to show a beneficial effect of NSAIDs on AD patients have been instead disappointing. Two small pilot trials have shown promising results with indomethacin (Rogers et al., 1993) and diclofenac (Scharf et al., 1999), but subsequent trials focusing on the attempt to reduce $\mathrm{AD}$ progression have failed to show any benefit (Aisen et al., 2003; Reines et al., 2004; Soininen et al., 2007).

The aim of the present study - as a part of a clinical trial on a wider population (Zanetti et al., 2006) - was to evaluate the hypothesis that long-term treatment with ibuprofen affects cortical sources of resting EEG rhythms in mild AD patients, as a neurophysiological reflection of the therapy. A special attention was devoted to the effect of the therapy on the cortical sources of delta rhythms, which are supposed to enhance in magnitude as a function of the functionality of cholinergic basal forebrain neurons projecting to hippocampus and fronto-parietal connections (Ebert and Kirch, 1998; Babiloni et al., 2006f). The working hypothesis is that anti-inflammatory effects of ibuprofen slow down both neurodegeneration and enhancement of delta sources. Resting EEG data were recorded in mild $\mathrm{AD}$ patients before and 1 year after ibuprofen or placebo treatment. Cortical sources of EEG rhythms were studied with the technique called low-resolution brain electromagnetic tomography (LORETA; Pascual-Marqui and Michel, 1994), successfully used in recent EEG studies on physiological and pathological brain aging (Babiloni et al., 2004, 2006a,b,c,d,e,f, 2007a,b,c, 2008; for a review see, Rossini et al., 2007).

\section{Methods}

\subsection{Subjects and diagnostic criteria}

The present EEG study derived from an ancillary physiological branch of a multicentre clinical trial granted by Italian Public Health Ministry (Zanetti et al., 2006). Financial resources for such an ancillary branch just allowed the EEG experiments in 23 mild
AD patients, who were blindly divided to the AD IBUPROFEN group $(N=13)$ and untreated AD PLACEBO group $(N=10)$. Furthermore, 24 cognitively normal Nold subjects were recruited to form a control group. All experiments were performed with the informed and overt consent of each participant or caregiver, in line with the Code of Ethics of the World Medical Association (Declaration of Helsinki) and the standards established by the Author's Institutional Review Board.

Probable AD was diagnosed according to NINCDS-ADRDA (McKhann et al., 1984). Patients underwent general medical, neurological and psychiatric assessments and were also rated with a number of standardized diagnostic and severity instruments that included mini mental state evaluation (MMSE; Folstein et al., 1975), Alzheimer Disease Assessment Scale-cognitive (ADAS-cog Italian version, Fioravanti et al., 1994), Clinical Dementia Rating Scale (CDR; Hughes et al., 1982), Clinical Dementia Rating sum of box score (CDR Sum-of-Boxes, Berg et al., 1988), Geriatric Depression Scale (GDS; Yesavage et al., 1982), Instrumental Activities of Daily Living scale (IADL; Lawton and Brodie, 1969), Basic Activities of Daily Living scale (BADL; Katz, 1983), Neuropsychiatry Inventory (NPI; Cummings et al., 1994), Beck Depression Inventory (BDI, Katz, 1998), and State Trait Anxiety Inventory (STAI Y-1, STAI Y-2; Speilberger, 1983).

Neuroimaging diagnostic procedures (CT or MRI) and complete laboratory analyses were carried out to exclude other causes of progressive or reversible dementias, in order to have a homogenous AD patient sample. The exclusion criteria included, in particular, any evidence of (i) frontotemporal dementia diagnosed according to criteria of Lund and Manchester Groups (1994); (ii) vascular dementia as diagnosed according to NINDS-AIREN criteria (Román et al., 1993); (iii) extra-pyramidal syndromes; (iv) Parkinson disease; (v) reversible causes of dementias; and (vi) Lewy body dementia according to the criteria by McKeith and colleagues (1999). The detection of the vascular component in dementia was accounted based on previous theoretical guidelines from our network (Frisoni et al., 1995; Galluzzi et al., 2005). AD patients were also excluded from the study if any of the following were present: allergy to non-steroidal anti-inflammatory drugs (NSAIDs); active gastritis or peptic ulcerative disease; renal and hepatic insufficiency; active inflammatory, infectious or neoplastic diseases; active COPD; CHF; history of or current alcohol abuse; previous chronic or prolonged use of NSAIDs and corticosteroids; active treatment with anticoagulants, corticosteroids, and COX2 inhibitors. Vitamin E, low-dose aspirin ( $325 \mathrm{mg} /$ day) and the occasional use of NSAIDs were permitted during the study, though all actual usage was recorded. In addition, patients taking stable doses of SSRI antidepressants, benzodiazepines, and neuroleptics were allowed into the study. To avoid the potentially confounding effects of anticholinesterase medications on the outcomes, all AD patients received a regular dose of Donepezil (Aricept or Memac 5-10 mg) for at least 3 months; other types of AChEI were not allowed. Furthermore, about $20 \%$ of the AD patients of both AD PLACEBO and AD IBUPROFEN groups took regular doses of SSRI antidepressants, benzodiazepines, and neuroleptics. Of note, Donepezil, benzodiazepines, antidepressant and/or neuroleptics were suspended for about $24 \mathrm{~h}$ before EEG recordings. This did not insure a complete washout of the drug, but made it comparable the drug status across the patients. Washed out of the drugs would have required a too long suspension of the drugs with high risks for the patients.

Duration of the ibuprofen or placebo (400 mg twice-daily) administration was 52 weeks (1 year). Once-daily $20 \mathrm{mg}$ esomeprazol (or placebo for the placebo arm) was concurrently administered for GI protection. Tablets of the active drug and the placebo were undistinguishable. Similarly, the gastroprotective agent and the relative placebo were also undistinguishable. Active 
drug tablets and relative placebos were supplied by Angelini SpA for Ibuprofen, and by Astra-Zeneca Pharmaceuticals for esomeprazole. Each participant received two boxes of study medication in a blister package and two bottles of gastroprotective agent (or placebo) with coded labels at baseline, and at 3-, 6-, 9-month visits, with sufficient medication to cover the 3-month period between follow-ups. At each visit the number of returned tablets was recorded for compliance assessment.

The Nold subjects were recruited mostly among non-consanguineous patients' relatives. All Nold subjects underwent physical and neurological examinations as well as cognitive screening. Subjects affected by chronic systemic illnesses, subjects receiving psychoactive drugs, and subjects with a history of present or previous neurological or psychiatric disease were excluded. All Nold subjects had a GDS score lower than 14 (no depression).

Table 1 summarizes demographic and clinical data of the recruited Nold and mild AD subjects. Four ANOVAs using the factor Group (Nold, AD) were computed to evaluate the presence or absence of statistically significant differences between the Nold and AD subjects for age, education, gender, and MMSE. No statistically significant difference for age, education, and gender were found $(p>0.3)$. As expected, the ANOVA for the MMSE score showed a statistically significant difference $(F(1,45)=117 ; p<0.0001)$, indicating that the MMSE values were higher in the Nold compared to the AD group.

Table 2 reports baseline demographic and clinical data of the mild AD patients, subdivided in the AD IBUPROFEN and AD PLACEBO groups. Twelve ANOVAs using the factor Group (AD IBUPROFEN and AD PLACEBO) were computed to evaluate the presence or absence of statistically significant differences between the AD IBUPROFEN and AD PLACEBO groups for age, education, gender, MMSE, CDR, CDR Sum-of-Boxes, GDS, IADL, BADL, NPI, BDI, STAI Y1, STAI Y2 . No statistically significant difference was found $(p>0.05)$. Of note, age, gender, and education were used as covariates in the statistical evaluation of cortical sources of EEG rhythms, to remove possible slight confounding effects.

\subsection{EEG recordings}

EEG data were recorded by specialized clinical units in the Nold and mild $\mathrm{AD}$ subjects at resting state (eyes-closed). The EEG recordings were performed $(0.3-70 \mathrm{~Hz}$ bandpass) from 19 electrodes positioned according to the International 10-20 System (i.e. Fp1, Fp2, F7, F3, Fz, F4, F8, T3, C3, Cz, C4, T4, T5, P3, Pz, P4, $\mathrm{T} 6, \mathrm{O} 1$, and $\mathrm{O2}$ ). A specific reference electrode was not imposed to the recording clinical units of this study, since preliminary data inspection and LORETA source analysis were carried out after EEG data were re-referenced to a common average reference. To monitor eye movements, the horizontal and vertical electrooculogram $(0.3-70 \mathrm{~Hz}$ bandpass) was also collected. All data were digitized in continuous recording mode (5 min of EEG; $256 \mathrm{~Hz}$ sampling rate). It is noteworthy that the EEG data were recorded before (Recording I) and about after 1 year (Recording II) of ibuprofen or placebo treatment in the mild AD patients. The EEG recordings were performed in the late morning. In order to keep constant the level of vigilance, an experimenter controlled online the sub-

Table 1

Demographic and neuropsychological data of interest of the normal elderly controls (Nold) and mild Alzheimer's disease (AD) subjects.

\begin{tabular}{lll}
\hline & Nold & $\mathrm{AD}$ \\
\hline$N$ & 24 & 23 \\
Age (years) & $74( \pm 1.4 \mathrm{SE})$ & $75.6( \pm 1.4 \mathrm{SE})$ \\
Education (years) & $6.7( \pm 0.6 \mathrm{SE})$ & $5.7( \pm 0.7 \mathrm{SE})$ \\
MMSE & $28.6( \pm 0.2 \mathrm{SE})$ & $21.8( \pm 0.6 \mathrm{SE})$ \\
Gender $(\mathrm{M} / \mathrm{F})$ & $7 / 17$ & $5 / 18$ \\
\hline
\end{tabular}

Table 2

Demographic and neuropsychological data of interest of the mild AD subjects, subdivided in AD IBUPROFEN (AD patients treated with ibuprofen) and AD PLACEBO (AD patients treated with placebo). Legend: MMSE, mini mental state evaluation; ADAS-cog, Alzheimer Disease Assessment Scale-cognitive; CDR, Clinical Dementia Rating Scale; CDR Sum-of-Boxes, Clinical Dementia Rating sum of box score; GDS, Geriatric Depression Scale; IADL, Instrumental Activities of Daily Living scale; BADL Basic Activities of Daily Living scale; NPI, Neuropsychiatry Inventory; BDI, Beck Depression Inventory; STAI Y1 and Y2, State Trait Anxiety Inventory Form Y1 and Form Y2.

\begin{tabular}{llll}
\hline & AD Ibuprofen & AD Placebo & ANOVA \\
\hline$N$ & 13 & 10 & \\
Age (years) & $75.7( \pm 2 \mathrm{SE})$ & $75.4( \pm 1.8 \mathrm{SE})$ & $p>0.9$ \\
Education (years) & $6( \pm 1.1 \mathrm{SE})$ & $5.3( \pm 0.7 \mathrm{SE})$ & $p>0.6$ \\
Gender (M/F) & $4 / 9$ & $1 / 9$ & $p>0.2$ \\
MMSE & $20.9( \pm 0.8 \mathrm{SE})$ & $23( \pm 0.8 \mathrm{SE})$ & $p>0.6$ \\
CDR & $0.8( \pm 0.1 \mathrm{SE})$ & $0.7( \pm 0.1 \mathrm{SE})$ & $p>0.1$ \\
CDR Sum-of-Boxes & $5( \pm 0.7 \mathrm{SE})$ & $3.6( \pm 0.5 \mathrm{SE})$ & $p>0.2$ \\
GDS & $8.3( \pm 1.5 \mathrm{SE})$ & $8.8( \pm 2 \mathrm{SE})$ & $p>0.8$ \\
IADL & $3.7( \pm 0.6 \mathrm{SE})$ & $5.5( \pm 0.7 \mathrm{SE})$ & $p>0.05$ \\
BADL & $5.7( \pm 0.2 \mathrm{SE})$ & $5.8( \pm 0.2 \mathrm{SE})$ & $p>0.9$ \\
ADAS-cog & $27.8( \pm 2.5 \mathrm{SE})$ & $21.5( \pm 2 \mathrm{SE})$ & $p>0.1$ \\
NPI & $9.5( \pm 2 \mathrm{SE})$ & $6.9( \pm 1.6 \mathrm{SE})$ & $p>0.4$ \\
BDI & $7.9( \pm 1.4 \mathrm{SE})$ & $6.8( \pm 1.4 \mathrm{SE})$ & $p>0.4$ \\
STAI Y1 & $39.8( \pm 2.1 \mathrm{SE})$ & $41.3( \pm 1.4 \mathrm{SE})$ & $p>0.6$ \\
STAI Y2 & $40.2( \pm 2.7 \mathrm{SE})$ & $37.1( \pm 2.3 \mathrm{SE})$ & $p>0.4$ \\
\hline
\end{tabular}

ject and the EEG traces. He verbally alerted the subject any time there were signs of behavioral and/or EEG drowsiness.

The recorded EEG data were analyzed and fragmented offline in consecutive epochs of $2 \mathrm{~s}$. The EEG epochs with ocular, muscular, and other types of artifact were preliminary identified by a computerized automatic procedure. The EEG epochs with sporadic blinking artifacts (less than $10 \%$ of the total) were corrected by an autoregressive method (Moretti et al., 2003). Two independent experimenters blind to the diagnosis manually confirmed the EEG segments accepted for further analysis. Of note, a special attention was devoted to avoid the inclusion of EEG segments and individual data sets with EEG signs of drowsiness or pre-sleep stages. Furthermore, the experimenters were blind to the diagnosis of the subjects at the moment of the preliminary EEG data analysis.

\subsection{Spectral analysis of the EEG data}

A digital FFT-based power spectrum analysis (Welch technique, Hanning windowing function, no phase shift) computed power density of the EEG rhythms with $0.5 \mathrm{~Hz}$ frequency resolution. The following standard band frequencies were studied: delta (2$4 \mathrm{~Hz})$, theta $(4-8 \mathrm{~Hz})$, alpha $1(8-10.5 \mathrm{~Hz})$, alpha $2(10.5-13 \mathrm{~Hz})$, beta $1(13-20 \mathrm{~Hz})$, and beta $2(20-30 \mathrm{~Hz})$. These band frequencies were chosen averaging those used in previous relevant EEG studies on dementia (Besthorn et al., 1997; Chiaramonti et al., 1997; Jelic et al., 1996; Leuchter et al., 1993; Rodriguez et al., 1999; Babiloni et al., 2004, Babiloni et al., 2006a,b,c,d,e, Babiloni et al., 2006f, $2007 a, a, b)$. Sharing of a frequency bin by two contiguous bands is a widely accepted procedure (Besthorn et al., 1997, Cook and Leuchter, 1996, Holschneider et al., 1999, Jelic et al., 1996, Kolev et al., 2002, Leuchter et al., 1993, Nobili et al., 1998, Pucci et al., 1997). Furthermore, this fits the theoretical consideration that near EEG rhythms may overlap at their frequency borders (Babiloni et al., 2004, 2006a,b,c,d,e,f, 2007a,b,c, 2008; Klimesch, 1996, 1999, Klimesch et al., 1997, 1998).

Choice of the fixed EEG bands did not account for individual alpha frequency (IAF) peak, defined as the frequency associated with the strongest EEG power at the extended alpha range (Klimesch, 1999). However, this should not affect the results, since most of the subjects had IAF peaks within the alpha 1 band $(8-10.5 \mathrm{~Hz})$. In particular, mean IAF peak at Recording I was $9.2 \mathrm{~Hz}$ ( \pm 0.1 stan- 
dard error, SE) in the Nold subjects, $9 \mathrm{~Hz}( \pm 0.4 \mathrm{SE})$ in the AD IBUPROFEN subjects, and $9.4 \mathrm{~Hz}( \pm 0.3 \mathrm{SE})$ in the AD PLACEBO subjects. Moreover, mean IAF peak at Recording II was $8.7 \mathrm{~Hz}( \pm 0.4 \mathrm{SE})$ in the AD IBUPROFEN subjects and $8.9 \mathrm{~Hz}( \pm 0.4 \mathrm{SE})$ in the AD PLACEBO subjects. To control for the effect of IAF on the EEG comparisons, the IAF peak was used as a covariate (together with age, education and gender) for further statistics.

Finally, the analysis of the delta band was restricted to $2-4 \mathrm{~Hz}$ for homogeneity with previously quoted field literature (Babiloni et al., 2004, 2006a,b,c,d,e,f, 2007a,b,c, 2008) and to avoid the residual effects of uncontrolled head movements - provoking artifacts in the lower delta band - especially in the mild AD subjects.

\subsection{Cortical source analysis of the EEG rhythms by LORETA}

Low-resolution electromagnetic source tomography (LORETA) was used for the EEG source analysis as provided at http://www.unizh.ch/keyinst/NewLORETA/LORETA01.htm (Pascual-Marqui and Michel, 1994; Pascual-Marqui et al., 1999, 2002). LORETA is a functional imaging technique belonging to a family of linear inverse solution procedures modeling 3D distributions of EEG sources (Pascual-Marqui et al., 2002). With respect to the dipole modeling of cortical sources, no a priori decision of the dipole position is required by the investigators in LORETA estimation. In a previous review paper, it has been shown that it was quite efficient when compared to other linear inverse algorithms like minimum norm solution, weighted minimum norm solution or weighted resolution optimization (Pascual-Marqui et al., 1999; Phillips et al., 2002; Yao and He, 2001). Finally, LORETA has been successfully used in recent EEG studies on pathological brain aging (Dierks et al., 2000; Babiloni et al., 2004, 2006a,b,c,d,e,f, 2007a,b,c, 2008).

LORETA computes 3D linear solutions (LORETA solutions) for the EEG inverse problem within a 3-shell spherical head model including scalp, skull, and brain compartments. The brain compartment is restricted to the cortical gray matter/hippocampus of a head model co-registered to the Talairach probability brain atlas and digitized at the Brain Imaging Center of the Montreal Neurological Institute (Talairach and Tournoux, 1988). This compartment includes 2394 voxels ( $7 \mathrm{~mm}$ resolution), each voxel containing an equivalent current dipole.

LORETA can be used from EEG data collected by low spatial sampling of 10-20 system (19 electrodes) when cortical sources are estimated from resting EEG rhythms (Anderer et al., 2003, 2004; Babiloni et al., 2004, 2006a,b,c,d,e,f, 2007a,b,c, 2008; Laufer and Pratt, 2003; Mulert et al., 2001). LORETA solutions consisted of voxel $z$-current density values able to predict EEG spectral power density at scalp electrodes, being a reference-free method of EEG analysis, in that one obtains the same LORETA source distribution for EEG data referenced to any reference electrode including common average. A normalization of the data was obtained by normalizing the LORETA current density at each voxel with the power density averaged across all frequencies $(0.5-45 \mathrm{~Hz})$ and across all 2394 voxels of the brain volume. After the normalization, the solutions lost the original physical dimension and were represented by an arbitrary unit scale. The general procedure fitted the LORETA solutions in a Gaussian distribution and reduced inter-subject variability (Nuwer, 1988; Leuchter et al., 1993).

Solutions of the EEG inverse problem are under-determined and ill-conditioned when the number of spatial samples (electrodes) is lower than that of the unknown samples (current density at each voxel). To account for that, the cortical LORETA solutions predicting scalp EEG spectral power density were regularized to estimate distributed rather than punctual EEG source patterns (PascualMarqui et al., 1999, 2002). In line with the low spatial resolution of the adopted technique, home-made MATLAB software averaged the amplitude of LORETA solutions for all voxels belonging to each macroregion of interest such as frontal, central, parietal, occipital, and temporal. Each of these macroregions of interest (ROIs) was constituted by all the voxels of the Brodmann areas listed in Table 3. The belonging of a LORETA voxel to a Brodmann area was defined by original LORETA package.

Finally, the main advantage of the regional analysis of LORETA solutions - using an explicit source model coregistered into Talairach space - was that our modeling could disentangle rhythms of contiguous cortical areas (namely those from the occipital source were disentangled with respect to those of the contiguous parietal and temporal sources, etc).

\subsection{Statistical analysis of the LORETA solutions}

Statistical comparisons were performed by ANOVA. Mauchley's test evaluated the sphericity assumption and the correction of the degrees of freedom was made by Greenhouse-Geisser procedure. Duncan test was used for post-hoc test comparisons $(p<0.05)$. In particular, the following three ANOVAs were performed.

A first ANOVA (EEG data) verified the control hypothesis, namely the sensitivity of the present LORETA approach. To this aim, the regional normalized LORETA solutions from the Nold and $\mathrm{AD}$ subjects at Recording I were used as an input for an ANOVA. Subjects' age, education, gender and IAF peak served as covariates. The ANOVA used the factors Group (Nold, mild AD; independent variable), Band (delta, theta, alpha 1, alpha 2, beta 1 , and beta 2 ), and ROI (central, frontal, parietal, occipital, and temporal). The control hypothesis was that the cortical sources of resting EEG rhythms are abnormal in the present $\mathrm{AD}$ patients. Specifically, it would be confirmed by the following two statistical results: (i) a statistical ANOVA effect including the factor Group $(p<0.05)$ and (ii) a post-hoc test indicating statistically significant differences of the (LORETA) EEG sources with the patterns Nold > mild AD or Nold < mild AD (Duncan test, $p<0.05$ ).

A second ANOVA design (MMSE data) tested the effects of the ibuprofen treatment on the global cognitive function ad revealed by MMSE score (i.e. the existence of MMSE differences across 1 year between the AD IBUPROFEN and AD PLACEBO groups). Since the population of $A D$ patients was relatively small for a clinical evaluation of the ibuprofen therapy, we simplified the ANOVA design using the difference between I MMSE and II MMSE (II MMSE minus I MMSE) as a dependent variable. The ANOVA factor was Group (AD IBUPROFEN, AD PLACEBO).

A third ANOVA design (EEG data) tested the working hypothesis, namely the effects of long-term ibuprofen treatment on the cortical sources of resting EEG rhythms (i.e. the existence of EEG differences across one year between the AD IBUPROFEN and AD PLACEBO groups). To simplify the ANOVA design, the ANOVA dependent variable was the difference of the regional normalized LORETA solutions in the Recording II and Recording I. The ANOVA factors were Group (AD IBUPROFEN, AD PLACEBO; independent variable), Band (delta, theta, alpha 1 , alpha 2 , beta 1 , and beta 2 ), and ROI (central, frontal, parietal, occipital, and temporal). The working hypothesis would be confirmed by the following two statistical results: (i) a statistical ANOVA effect including the factor Group $(p<0.05)$ and (ii) a posthoc test indicating statistically significant differences of the (LORETA) EEG sources with the patterns AD IBUPROFEN $>$ AD PLACEBO or AD IBUPROFEN $<$ AD PLACEBO (Duncan test, $p<0.05$ ).

\section{Results}

\subsection{Cortical sources of EEG rhythms as estimated by LORETA}

For illustrative purposes, Fig. 1 maps the grand average of the LORETA solutions (i.e. relative current density at cortical voxels) 
Table 3

Brodmann areas included in the cortical regions of interest (ROIs) of the present study. LORETA solutions were collapsed in frontal, central, parietal, occipital, and temporal ROIs.

\begin{tabular}{ll}
\hline LORETA Brodmann areas into the regions of interest (ROIs) \\
Frontal & $8,9,10,11,44,45,46,47$ \\
Central & $1,2,3,4,6$ \\
Parietal & $5,7,30,39,40,43$ \\
Temporal & $20,21,22,37,38,41,42$ \\
Occipital & $17,18,19$
\end{tabular}

modeling cortical sources of delta, theta, alpha 1 , alpha 2 , beta 1 and beta 2 rhythms in the Nold and mild AD groups. The Nold group presented alpha 1 sources with the maximal values of amplitude distributed in parietal and occipital regions. Delta, theta, and alpha 2 sources had moderate amplitude values when compared to alpha 1 sources. Furthermore, beta 1 and beta 2 sources were characterized by lowest amplitude values. Compared to the Nold group, the mild $\mathrm{AD}$ group showed a decrease in amplitude of the parietal, occipital, and temporal alpha 1 and alpha 2 sources. Furthermore, the mild AD group showed an amplitude increase of widespread delta sources.

For illustrative purpose, Fig. 2 maps the grand average of the LORETA solutions (i.e. relative current density at cortical voxels) modeling cortical sources of delta, theta, alpha 1 , alpha 2 , beta 1 , and beta 2 rhythms in the AD IBUPROFEN and AD PLACEBO groups at the Recording I and Recording II. At the Recording I, the two groups showed no clear difference in the LORETA solutions. At the Recording II, there was greater magnitude of widespread delta sources in the AD PLACEBO group than in the AD IBUPROFEN group.

\subsection{Statistical comparisons}

The ANOVA for the evaluation of the control hypothesis on the LORETA solutions showed a statistically significant interaction $(F(20,900)=1.98$; MSe $=0.6 ; \mathrm{p}<0.006)$ among the factors Group (Nold and mild AD), Band (delta, theta, alpha 1, alpha 2, beta 1 , and beta 2), and ROI (central, frontal, parietal, occipital, and temporal). Fig. 3 shows the mean regional normalized LORETA solutions relative to this statistical ANOVA interaction. In the figure, the regional normalized LORETA solutions had the shape of EEG relative

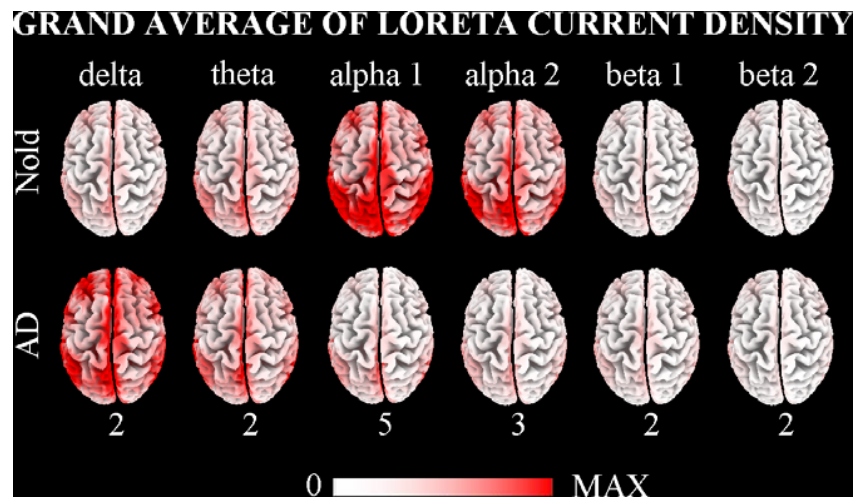

Fig. 1. Grand average of the LORETA solutions (i.e. normalized relative current density at the cortical voxels) modeling cortical sources of delta, theta, alpha 1 alpha 2, beta 1 , and beta 2 rhythms in the Nold and mild AD subjects. In this control analysis, the AD group included the AD IBUPROFEN and AD PLACEBO subjects as a single group. The left side of the maps (top view) corresponds to the left hemisphere. Legend: LORETA, low-resolution brain electromagnetic tomography Color scale: all power estimates were scaled based on the averaged maximum value (i.e. alpha 1 power value of occipital region in the Nold subjects). The maximal value of the LORETA solution is reported under each column. power spectra. Notably, profile and magnitude of these spectra in the Nold and mild AD groups differed across diverse cortical macro-regions, thus supporting the idea that scalp EEG rhythms are generated by a distributed pattern of cortical sources. The Duncan planned post-hoc testing showed that: (i) the source pattern Nold $<$ mild AD was fitted by frontal delta sources $(p<0.03$ ); (ii) the source pattern Nold $>$ mild AD was fitted by parietal, occipital, temporal alpha 1 , and occipital alpha 2 sources $(p<0.004$ to $0.000003)$. These results demonstrated the sensitivity of the present LORETA approach, namely the existence of significant EEG source differences between the Nold and mild AD groups.

The ANOVA for the evaluation of the long-term ibuprofen effects on MMSE score showed no statistically significant difference between the AD IBUPROFEN and AD PLACEBO groups ( $p>0.1$ ), possibly due to the small AD populations used for this EEG study.

The ANOVA for the evaluation of the effects of ibuprofen treatment on cortical sources of EEG rhythms pointed to a statistically significant interaction $(F(5,105)=2.22$; MSe $=1.9$; $\mathrm{p}<0.05)$ between the factors Group (AD PLACEBO and AD IBUPROFEN) and Band (delta, theta, alpha 1, alpha 2, beta 1, and beta 2). Fig. 4 shows the mean difference of regional normalized LORETA solutions between the Recording II and Recording I relative to this statistical ANOVA interaction. The Duncan planned post-hoc testing showed that the source pattern AD PLACEBO > AD IBUPROFEN was fitted by delta sources $(p<0.01)$. In Fig. 5 , a scatterplot illustrates the difference of the delta power between the Recording II and Recording I for the patients of the AD PLACEBO group and for the patients of the AD IBUPROFEN group. This scatterplot shows that the majority

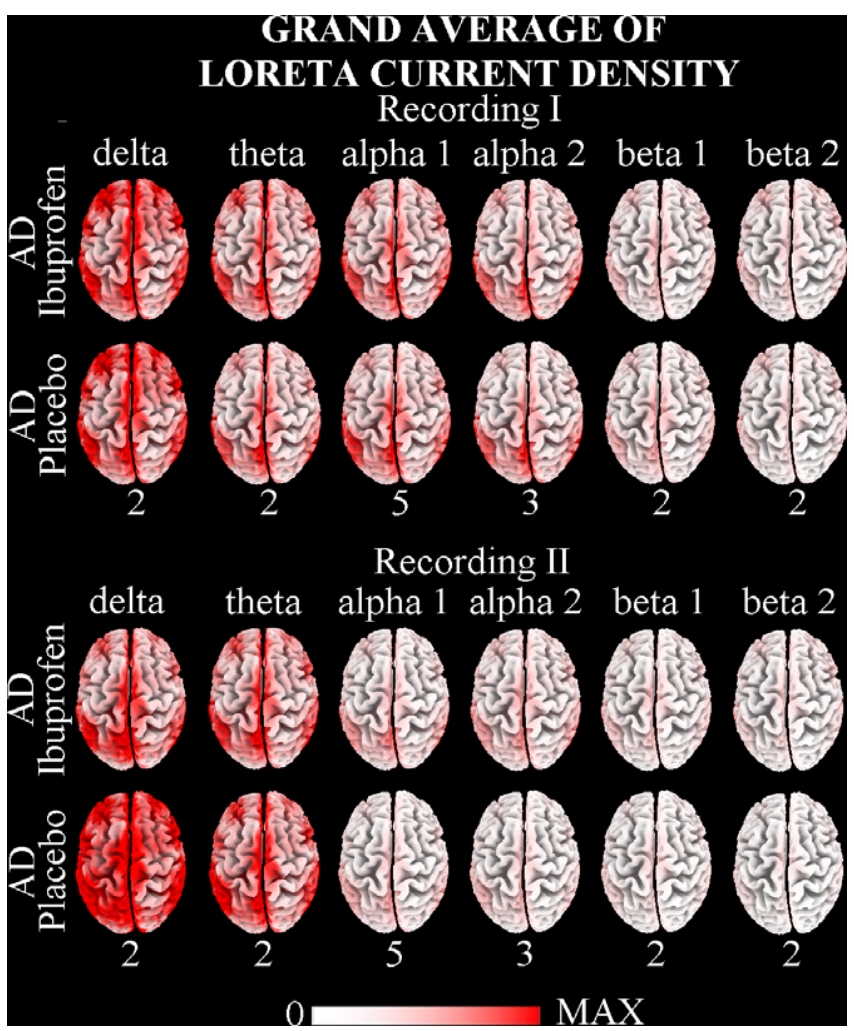

Fig. 2. Grand average of the LORETA solutions (i.e. normalized relative current density at the cortical voxels) modeling cortical sources of delta, theta, alpha 1, alpha 2, beta 1, and beta 2 rhythms in the AD IBUPROFEN and AD PLACEBO groups during the Recording I (before the therapy or placebo) and Recording II (after about 1 year of the therapy or placebo). The left side of the maps (top view) corresponds to the left hemisphere. Color scale: all power estimates were scaled based on the averaged maximum value (i.e. alpha 1 power value of occipital region during Recording I). The maximal value of power is reported under each column. 


\section{STATISTICAL ANOVA INTERACTION AMONG GROUP, BAND AND ROI}
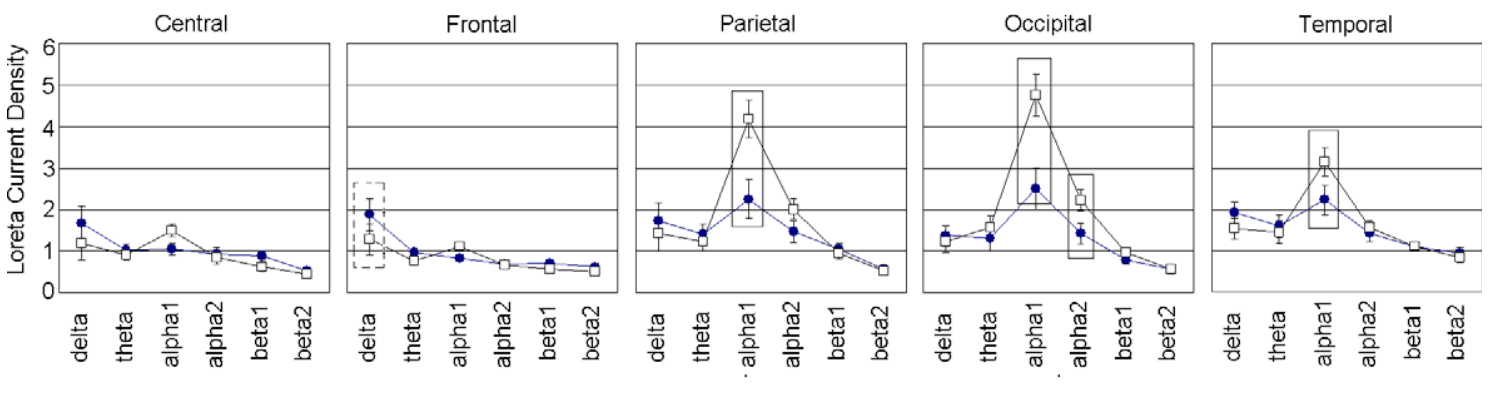

$\rightarrow$ Nold $\multimap-A D$

$=$ Nold $>A D(p<0.004)$

$\left[\begin{array}{c}\cdots-\cdots \\ -\cdots\end{array}\right]=$ Nold $<$ AD $(p<0.03)$

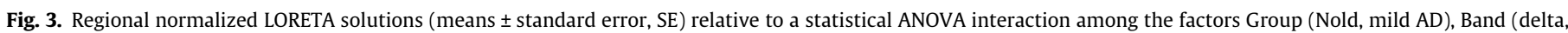

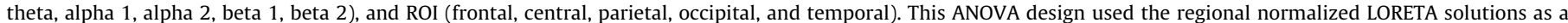

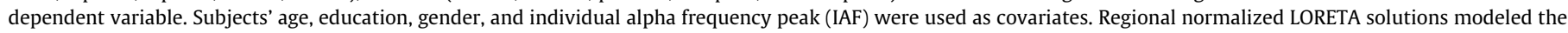

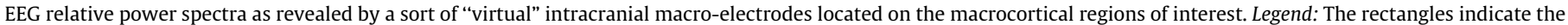
cortical regions and frequency bands in which LORETA solutions presented statistically significant LORETA patterns Nold $\neq$ mild AD ( $p<0.05)$.

of the AD PLACEBO patients presented positive values indicating that the delta power increased from the Recording I to the Recording II. In contrast, the majority of the AD PLACEBO patients presented near zero or negative values indicating that the delta power remained stable or decreased from the Recording I to the Recording II. To test the functional meaning of these results, a correlation analysis was performed between the difference of the values of MMSE (i.e. global cognitive function) or CDR (i.e. global clinical status) and the difference of the delta power between the Recording II and Recording I for all AD patients as a whole group. The results showed a statistically significant correlation only between the difference of the values of CDR (i.e. global clinical status) and the difference of the delta power between the Recording II and Recording I for all AD patients as a whole group (Spearman test, $p<0.025$, corrected for two analyses; see Fig. 6). The higher the positive values of the delta power difference (i.e. the increase of the delta power from the Recording I to the Recording II) the lower the values of the CDR difference (i.e. the decrease of the CDR from

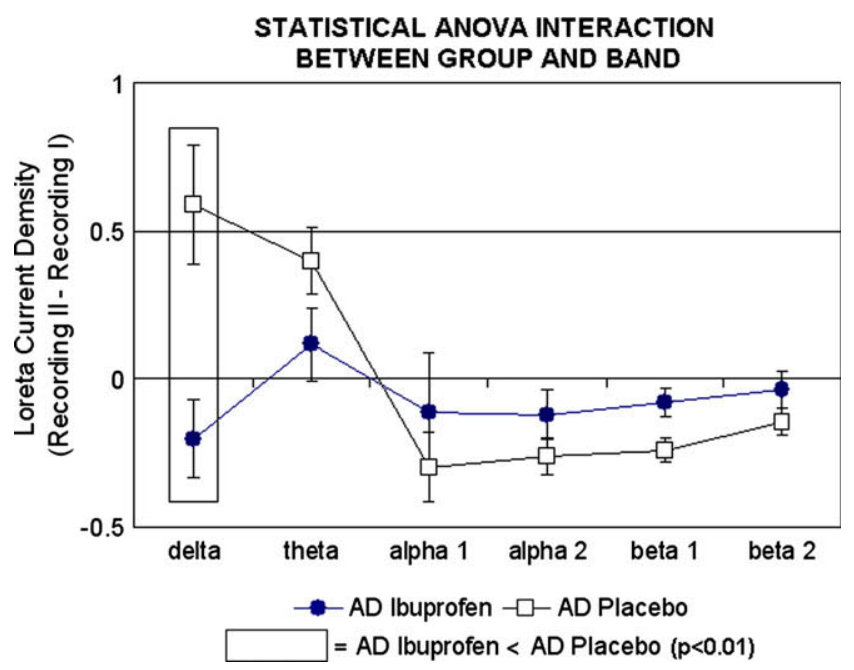

Fig. 4. Normalized LORETA solutions (means \pm standard error, SE) relative to a statistical ANOVA interaction among the factors Group (AD PLACEBO, AD IBUPROFEN), and Band (delta, theta, alpha 1, alpha 2, beta 1, and beta 2). This ANOVA design used the differences of the regional normalized LORETA solutions between recordings I and II (Recording II minus Recording I) as a dependent variable. Subjects' age, education, gender, and individual alpha frequency peak (IAF) were used as covariates. Legend: The rectangles indicate the frequency bands in which LORETA solutions presented statistically significant LORETA patterns AD PLACEBO $\neq$ AD IBUPROFEN $(p<0.05)$. the Recording I to the Recording II). These results confirmed the working hypothesis, namely the existence of differences in cortical sources of EEG rhythms across one year between the AD PLACEBO and AD IBUPROFEN groups, as a possible reflection of the neuroprotective action of the anti-inflammatory therapy. Specifically, one year after the beginning of the ibuprofen treatment, the amplitude of delta sources increased in the AD PLACEBO group, whereas it remained stable in the AD IBUPROFEN group.

\subsection{Control analyses}

As reported above, the long-term ibuprofen treatment did not affect global cognitive function as revealed by MMSE score. A first control analysis evaluated the effects of the ibuprofen treatment on another typical index of global cognitive function in elderly subjects, namely the total score of Alzheimer Disease Assessment Scale-cognitive (ADAS-cog Italian version, Fioravanti et al., 1994). Indeed, the total score of ADAS-cog is a typical endpoint of clinical trials on $\mathrm{AD}$, since it probes the global severity of cognitive symptoms in $\mathrm{AD}$ (for review see: Birks, 2006; Birks and Flicker, 2006; Harrison, 2007; Wesnes, 2008). The Italian version of ADAS-cog consists of 11 tasks measuring the impairment of memory, language, praxis, attention and other abilities that are often referred to as the core cognitive symptoms of AD (Fioravanti et al., 1994; Barone et al., 2008; Rozzini et al., 2008). To assess the effects of the ibuprofen treatment on ADAS-cog, we performed a ANOVA testing the difference of ADAS-cog total score across 1 year between the AD IBUPROFEN and AD PLACEBO groups. The difference of the total score between the baseline ADAS-cog and follow up

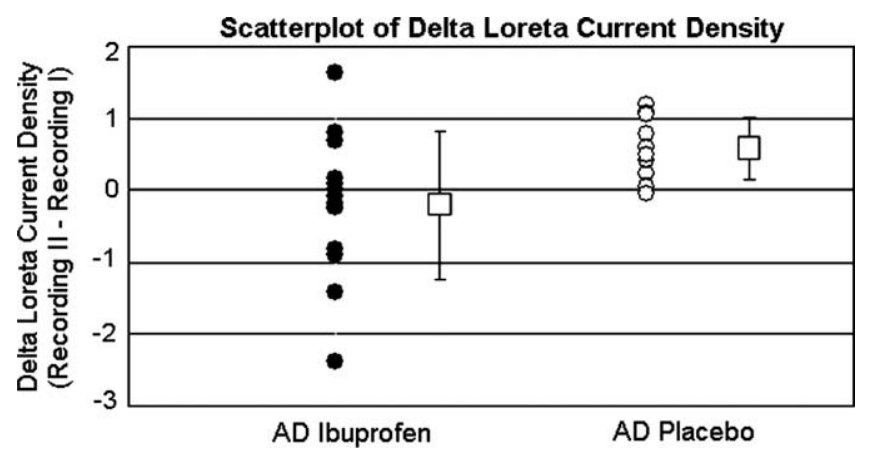

Fig. 5. Scatterplot illustrating the difference of the delta power between the Recording II and Recording I for the patients of the AD PLACEBO group and for the patients of the AD IBUPROFEN group. 
SCATTERPLOT BETWEEN DELTA LORETACURRENT DENSITY AND CLINICAL DEMENTIA RATING TOTAL SCORE (CDR)

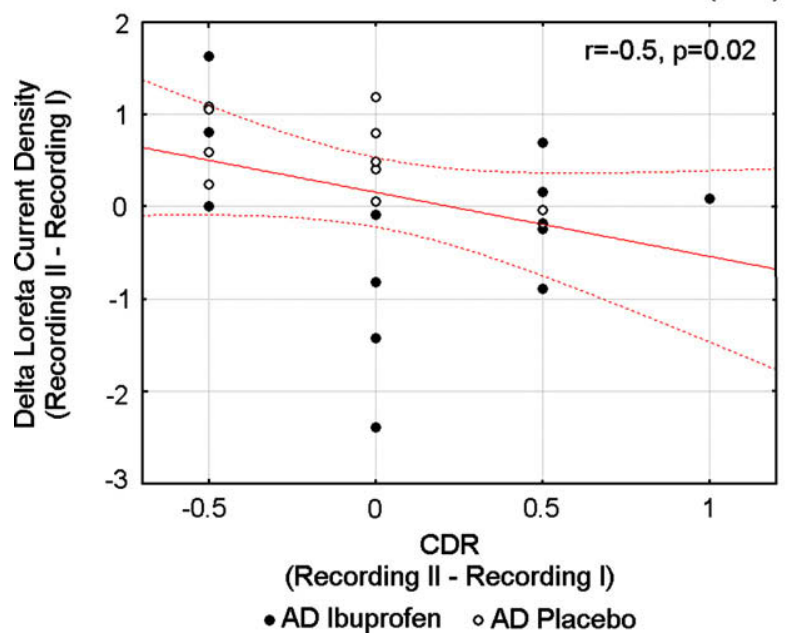

Fig. 6. Scatterplot illustrating statistically significant correlation between the difference of the values of CDR (i.e. global clinical status) and the difference of the delta power between the Recording II and Recording I for all AD patients as a whole group.

ADAS-cog (II ADAS-cog minus I ADAS-cog) was used as a dependent variable, whereas the ANOVA factor was Group (AD IBUPROFEN, AD PLACEBO). This ANOVA design showed no statistically significant difference between the AD IBUPROFEN and AD PLACEBO groups $(p>0.5)$. These results confirm those obtained using MMSE score, namely 1 -year ibuprofen treatment did not affect global cognitive function in our group of AD patients. Unlikely, we could have access only to the total score of ADAS-cog but not to the values of the single tests.

Main results showed that cortical sources of delta rhythms increased in magnitude from the baseline (Recording I) to followup (Recording II) in the majority of the AD PLACEBO patients, whereas those sources remained stable or decreased in amplitude from the baseline (Recording I) to follow-up (Recording II) in the majority of the AD IBUPROFEN patients. One may argue that these results were merely due to the use of the difference of the regional normalized LORETA solutions in the Recording II and Recording I as a dependent variable. To address this issue, the regional normalized delta LORETA solution was used as a dependent variable for a control ANOVA. The ANOVA factors were Group (AD IBUPROFEN, AD PLACEBO; independent variable), Recording (Recording I, Recording II), Band (delta, theta, alpha 1, alpha 2, beta 1, and beta 2 ), and ROI (central, frontal, parietal, occipital, and temporal). Subjects' age, education, gender, and IAF were used as covariates. The ANOVA showed a statistically significant interaction $(F(5,105)=2.6$; $\mathrm{MSe}=0.6 ; p<0.05)$ among the factors Group, Recording, Band, and ROI (see Fig. 7). The Duncan planned posthoc testing showed that the amplitude of the cortical delta sources was stronger at the Recording II than Recording I in the AD PLACEBO group ( $p<0.007)$. On the contrary, the amplitude of the delta sources did not differ at the Recording I and Recording II in the AD IBUPROFEN group $(p>0.3)$. These results confirmed that at the 1year follow-up, the amplitude of the cortical delta sources increased in the AD PLACEBO group but not in the AD IBUPROFEN group.

To further exclude that baseline delta sources in the AD IBUPROFEN and AD PLACEBO groups affected the main results of the present study, the regional normalized delta LORETA solutions from the AD PLACEBO and AD IBUPROFEN subjects at Recording I were used as an input for a control ANOVA. Subjects' age, education, gender and IAF peak served as covariates. The ANOVA factors were Group (AD IBUPROFEN, AD PLACEBO; independent variable) and ROI (central, frontal, parietal, occipital, and temporal). The ANOVA showed neither a main effect of the factor Group $(p>0.7)$ nor a statistical interaction between Group and ROI ( $p>0.3)$. These results showed that the cortical sources of delta EEG rhythms at baseline were substantially similar in the AD PLACEBO and AD IBUPROFEN groups and cannot account for the main results of this study. Moreover, we repeated the main ANOVA using baseline delta sources as an additional covariate. As in the main ANOVA, the control ANOVA showed a statistically significant interaction $(p<0.05)$ between the factors Group (AD PLACEBO and AD IBUPROFEN) and Band (delta, theta, alpha 1, alpha 2, beta 1, and beta 2 ). The Duncan planned post-hoc testing showed that the source pattern AD PLACEBO > AD IBUPROFEN was fitted by delta sources $(p<0.01)$. Therefore, these results showed that the delta source differences across 1;year between the AD IBUPROFEN and AD PLACEBO groups were not affected by the amplitude of delta sources at baseline in the two groups.

\section{Discussion}

In the preliminary control analysis, the present mild AD subjects were considered as a single AD group, to compare cortical sources of resting EEG rhythms (LORETA solutions; I Recordings) with those of the Nold group. With reference to the Nold group, the mild $A D$ group was characterized by (i) a marked amplitude decrease of the alpha 1 sources in parietal, occipital, and temporal areas; (ii) an amplitude decrease of the occipital alpha 2 sources; and (iii) an amplitude increase of the frontal delta sources. These control results are globally in line with previous evidence showing a decrement of alpha rhythms in AD compared to Nold subjects (Dierks et al., 1993, 2000; Jelic et al., 1996, 2000; Rodriguez et al., 1999; Huang et al., 2000; Babiloni et al., 2006a,b,c,d,e,f, 2007a,b,c, 2008), and an enhancement of the delta rhythms in AD compared to Nold subjects (bibgrp1; Jelic et al., 2000; Wolf et al., 2003; Babiloni et al., 2004, 2006a,b,c,d,e,f, Babiloni et al., 2007a,b,c, 2008).

The main analysis of the present study demonstrated a relationship between long-term ibuprofen treatment and cortical sources of resting EEG rhythms in mild AD patients. It was shown that cortical sources of delta rhythms globally increased in amplitude after the placebo treatment, as a sign of disease progression. On the contrary, the amplitude of cortical delta sources remained stable or

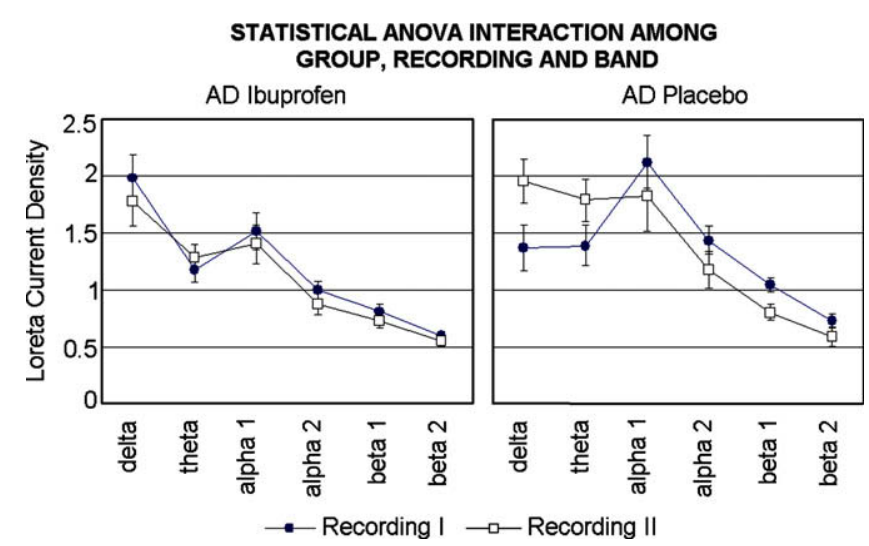

Fig. 7. Normalized LORETA solutions (means \pm standard error, SE) relative to a statistical ANOVA interaction among the factors Group (AD PLACEBO and AD IBUPROFEN), Recording (Recording I and Recording II), and Band (delta, theta, alpha 1 , alpha 2 , beta 1 , and beta 2 ). This ANOVA design used the regional normalized LORETA solutions as a dependent variable. Subjects' age, education, gender, and individual alpha frequency peak (IAF) were used as covariates. Legend: The rectangles indicate the frequency bands in which LORETA solutions presented statistically significant LORETA patterns Recording I $\neq$ Recording II $(p<0.05)$. 
decreased in the majority of the $\mathrm{AD}$ patients after the ibuprofen treatment. These results suggest an effect of the ibuprofen therapy on the generation of pathological cortical delta rhythms at the resting state, which might unveil one of the physiological action mechanisms of NSAIDs in AD. However, the present results should be treated with some caution due to the small amount of enrolled AD patients $(N=23)$. Furthermore, it cannot be entirely excluded that at the follow-up, cortical delta rhythms of some AD IBUPROFEN patients remained substantially stable for other reasons than the ibuprofen treatment.

Why did long-term ibuprofen treatment affect cortical sources of delta rhythms in mild AD patients? It can be speculated that the physiological mechanism is related to the neuroprotective role of NSAIDs such as ibuprofen on the risk of developing (Andersen et al., 1995; Anthony et al., 2000; Broe et al., 2000; Stewart et al., 1997; In 't Veld et al., 1998; Zandi et al., 2002). This role might be due to antiamyloidogenic effects of a therapy contrasting chronic inflammatory and immunity cascades in structures of central nervous system prone to neurodegeneration provoked by environmental neurotoxins, abnormal/incomplete development of myelination, and/or low levels of neurotrophic factors at cholinergic hippocampal and cortical pathways (Lim et al., 2000; Weggen et al., 2001; Sarter and Bruno, 2002). Such neuroprotection of ibuprofen might indirectly influence thalamocortical and cortico-cortical (mainly cholinergic) systems that produce delta rhythms (Sarter and Bruno, 2002; Kobayashi and Tadashi, 2002). In the condition of slow-wave sleep, corticofugal slow oscillations $(<1 \mathrm{~Hz})$ are effective in grouping thalamic-generated delta rhythms (1$4 \mathrm{~Hz}$; Steriade, 2003). In the condition of brain arousal, delta rhythms are blocked by the inhibition of oscillators within, respectively, reticulothalamic (7-14 Hz), thalamo-cortical (1-4 Hz), and intracortical $(<1 \mathrm{~Hz})$ neuronal circuits. Delta rhythms are replaced by fast (beta and gamma) cortical oscillations, which are mainly induced by cholinergic basal forebrain inputs to hippocampus and cortex as well as by thalamocortical projections (Steriade, 2003; Steriade et al., 1996).

Keeping in mind the mentioned theoretical framework, it can be speculated that a long-term ibuprofen treatment slightly slows down the $\mathrm{AD}$ neurodegenerative processes revealed by the increase of cortical delta rhythms. In AD patients, such an increase might be associated with a loss of cholinergic basal forebrain neurons projecting to hippocampus and fronto-parietal connections (Helkala et al., 1996; Holschneider et al., 1999; Mesulam et al., 2004), rather than with a loss of cholinergic brainstem neurons projecting to thalamus (Mash et al., 1985; Geula and Mesulam, 1989; Geula and Mesulam, 1996; Geula et al., 1999; Tanaka et al., 2003; Mesulam et al., 2004). The cholinergic basal forebrain neurons would be the main responsible together with serotoninergic neurons of the replacement of delta rhythms by fast EEG rhythms during wakefulness (Dringenberg, 2000; Dringenberg et al., 2002). The present results are also compatible with the enhancement of resting delta rhythms due to wide atrophy in mesial-temporal, posterior, and/or frontal areas of AD patients (Fernandez et al., 2003; Babiloni et al., 2006e) as well as to experimental lesions of basal forebrain in animals (Stewart et al., 1984; Buzsaki et al., 1988; Ray and Jackson, 1991). However, resting delta rhythms can be also pathologically enhanced by non-AD lesions of thalamus and brainstem provoked by cerebral vascular, traumatic, and tumor processes (Gloor et al., 1977; Harmony et al., 1993; Murri et al., 1998; deJongh et al., 2003; Hensel et al., 2004).

The present results showed a dissociation between the effects of the ibuprofen treatment on the global clinical and cognitive conditions. Indeed, the amplitude of cortical delta rhythms from the baseline to the 1-year follow-up was related to the global clinical status as probed by CDR score but to the global cognitive function as probed by MMSE and ADAS-cog. The higher the positive values of the delta power difference (i.e. the increase of the delta power from the baseline to the follow up), the lower the values of the CDR difference (i.e. the decrease of the CDR from the baseline to the follow up). An open question is why the long-term ibuprofen treatment did not affect global cognitive function. The number of the enrolled AD patients $(N=23)$ could be insufficient to investigate the complex relationships among resting delta rhythms, neurodegenerative processes, and higher order functions. Furthermore, both MMSE and ADAS-cog probe subjects' global cognitive skills but they do not allow probing single dimensions of higher order functions. Neuropsychological effects of the ibuprofen treatment might regard single cognitive functions or patients' subpopulations suffering from peculiar chronic inflammation at central nervous system. An alternative tentative explanation is the ibuprofen treatment might require longer time of administration to produce effects on cognitive functions (Anthony et al., 2000; Broe et al., 2000; Stewart et al., 1997; Zandi et al., 2002). To address these issues, future investigations might include (i) the prolongation of the ibuprofen treatment to 2 years in a large amount of patients and (ii) the evaluation of single cognitive tests exploring attention, spatial abilities, executive functions, and episodic memory in both baseline and follow-up.

In conclusion, we evaluated the hypothesis that long-term (1 year) ibuprofen treatment affects cortical sources of EEG rhythms in mild AD patients. Results showed that, in the AD PLACEBO group, cortical sources of delta rhythms was greater in magnitude at follow-up than baseline recordings, as a sign of disease progression. On the contrary, the amplitude of delta sources remained stable in the AD IBUPROFEN group. These results suggest that in mild AD patients, a long-term ibuprofen treatment slightly slows down the neurodegenerative processes revealed by cortical sources of delta rhythms. They also motivate future investigations with larger population and extended neuropsychological testing, to study the fine relationships among ibuprofen treatment, AD neurodegenerative processes, cortical sources of delta rhythms, higher order functions, and clinical picture.

\section{Acknowledgements}

The research was granted by the Association Fatebenefratelli for Research (AFaR) and Tosinvest Sanità. We also thank Angelini SpA and Astra-Zeneca Pharmaceuticals for the supply of active drug tablets and relative placebo.

\section{References}

Aisen PS, Schafer KA, Grundman M, Pfeiffer E, Sano M, Davis KL, et al. Effects of rofecoxib or naproxen vs placebo on Alzheimer disease progression: a randomized controlled trial. JAMA 2003;289(21):2819-26.

Akiyama H, Barger S, Barnum S, Bradt B, Bauer J, Cole GM, et al. Inflammation and Alzheimer's disease. Neurobiol Aging 2000;21(3):383-421 [review].

Anderer P, Saletu B, Semlitsch HV, Pascual-Marqui RD. Non-invasive localization of P300 sources in normal aging and age-associated memory impairment. Neurobiol Aging 2003;24(3):463-79.

Anderer P, Saletu B, Saletu-Zyhlarz G, Gruber D, Metka M, Huber J, et al. Brain regions activated during an auditory discrimination task in insomniac postmenopausal patients before and after hormone replacement therapy: low-resolution brain electromagnetic tomography applied to event-related potentials. Neuropsychobiology 2004;49(3):134-53.

Andersen K, Launer LJ, Ott A, Hoes AW, Breteler MM, Hofman A. Do nonsteroidal anti-inflammatory drugs decrease the risk for Alzheimer's disease? The Rotterdam study. Neurology 1995;45(8):1441-5.

Anthony JC, Breitner JC, Zandi PP, Meyer MR, Jurasova I, Norton MC, et al. Reduced prevalence of $\mathrm{AD}$ in users of NSAIDs and H2 receptor antagonists: the Cache County study. Neurology 2000;54(11):2066-71.

Babiloni C, Binetti G, Cassetta E, Cerboneschi D, Dal Forno G, Del Percio C, et al Mapping distributed sources of cortical rhythms in mild Alzheimer's disease. A multi-centric EEG study. Neurolmage 2004;22(1):57-67.

Babiloni C, Binetti G, Cassarino A, Dal Forno G, Del Percio C, Ferreri F, et al. Sources of cortical rhythms in adults during physiological aging: a multi-centric EEG study. Hum Brain Mapp 2006a;27(2):162-72. 
Babiloni C, Binetti G, Cassetta E, Dal Forno G, Del Percio C, Ferreri F, et al. Sources of cortical rhythms change as a function of cognitive impairment in pathological aging: a multi-centric study. Clin Neurophysiol 2006b;117(2):252-68.

Babiloni C, Benussi L, Binetti G, Bosco P, Busonero G, Cesaretti S, et al. Genotype (cystatin C) and EEG phenotype in Alzheimer disease and mild cognitive impairment: a multicentric study. Neuroimage 2006c;29(3):948-64.

Babiloni C, Benussi L, Binetti G, Cassetta E, Dal Forno G, Del Percio C, et al. Apolipoprotein $\mathrm{E}$ and alpha brain rhythms in mild cognitive impairment: a multicentric EEG study. Ann Neurol 2006d;59(2):323-34

Babiloni C, Frisoni G, Steriade M, Bresciani L, Binetti G, Del Percio C, et al. Fronta white matter volume and delta EEG sources negatively correlate in awake subjects with mild cognitive impairment and Alzheimer's disease. Clin Neurophysiol 2006e;117(5):1113-29.

Babiloni C, Cassetta E, Dal Forno G, Del Percio C, Ferreri F, Ferri R, et al. Donepezil effects on sources of cortical rhythms in mild Alzheimer's disease: responders vs. non-responders. Neuroimage 2006f;31(4):1650-65.

Babiloni C, Squitti R, Del Percio C, Cassetta E, Ventriglia MC, Ferreri F, et al. Free copper and resting temporal EEG rhythms correlate across healthy, mild cognitive impairment, and Alzheimer's disease subjects. Clin Neurophysio 2007a;118(6):1244-60.

Babiloni C, Cassetta E, Binetti G, Tombini M, Del Percio C, Ferreri F, et al. Resting EEC sources correlate with attentional span in mild cognitive impairment and Alzheimer's disease. Eur J Neurosci 2007b;25(12):3742-57.

Babiloni C, Bosco P, Ghidoni R, Del Percio C, Squitti R, Binetti G, et al. Homocysteine and EEG rhythms in Alzheimer disease: a multicentric study. Neuroscience 2007c;145(3):942-54.

Babiloni C, Frisoni G, Pievani M, Toscano L, Del Percio C, Geroldi C, et al. White matter vascular lesions correlate with alpha EEG sources in mild cognitive impairment. Neuropsychologia 2008;46(6):1707-20.

Barone P, Burn DJ, van Laar T, Hsu C, Poewe W, Lane RM. Rivastigmine versus placebo in hyperhomocysteinemic Parkinson's disease dementia patients. Mov Disord 2008;23(11):1532-40.

Beard CM, Kottke TE, Annegers JF, Ballard DJ. The Rochester coronary heart disease project: effect of cigarette smoking, hypertension, diabetes, and steroidal estrogen use on coronary heart disease among 40- to 59-year-old women, 1960 through 1982. Mayo Clin Proc 1989;64(12):1471-80.

Berg L, Miller JP, Storandt M, Duchek J, Morris JC, Rubin EH, et al. Mild senile dementia of the Alzheimer's type. 2: Longitudinal assessment. Ann Neurol 1988;23:477-84.

Besthorn C, Zerfass R, Geiger-Kabisch C, Sattel H, Daniel S, Schreiter-Gasser U, et al. Discrimination of Alzheimer's disease and normal aging by EEG data Electroencephalogr Clin Neurophysiol 1997;103(2):241-8.

Birks J. Cholinesterase inhibitors for Alzheimer's disease. Cochrane Database Syst Rev 2006(1):CD005593 [review].

Birks J, Flicker L. Donepezil for mild cognitive impairment. Cochrane Database Syst Rev 2006;3:CD006104 [review].

Brassen S, Adler G. Short-term effects of acetylcholinesterase inhibitor treatment on EEG and memory performance in Alzheimer patients: an open, controlled trial. Pharmacopsychiatry 2003;36:304-8.

Broe GA, Grayson DA, Creasey HM, Waite LM, Casey BJ, Bennett HP, et al. Antiinflammatory drugs protect against Alzheimer disease at low doses. Arch Neurol 2000;57(11):1586-91

Buzsaki G, Bickford RG, Ponomareff G, Thal LJ, Mandel R, Gage FH. Nucleus basalis and thalamic control of neocortical activity in the freely moving rat. J Neurosci 1988;8(11):4007-26.

Chiaramonti R, Muscas GC, Paganini M, Muller TJ, Fallgatter AJ, Versari A, et al Correlations of topographical EEG features with clinical severity in mild and moderate dementia of Alzheimer type. Neuropsychobiology 1997;36(3):153-8

Cook IA, Leuchter AF. Synaptic dysfunction in Alzheimer's disease: clinical assessment using quantitative EEG. Behav Brain Res 1996;78(1):15-23.

Cummings JL, Mega M, Gray K, Rosenberg-Thompson S, Carusi DA, Gornbein J. The neuropsychiatric inventory: comprehensive assessment of psychopathology in dementia. Neurology 1994;44:2308-14.

deJongh A, Baayen JC, de Munck JC, Heethaar RM, Vandertop WP, Stam CJ. The influence of brain tumor treatment on pathological delta activity in MEG. Neuroimage 2003;20(4):2291-301.

Dierks T, Ihl R, Frolich L, Maurer K. Dementia of the Alzheimer type: effects on the spontaneous EEG described by dipole sources. Psychiatry Res 1993;50(3):51-162.

Dierks T, Jelic V, Pascual-Marqui RD, Wahlund LO, Julin P, Linden DEJ, et al. Spatial pattern of cerebral glucose metabolism (PET) correlates with localization of intracerebral EEG-generators in Alzheimer's disease. Clin Neurophysiol 2000;111:1817-24

Dringenberg HC. Alzheimer's disease: more than a 'cholinergic disorder' - evidence that cholinergic-monoaminergic interactions contribute to EEG slowing and dementia. Behav Brain Res 2000;115:235-49.

Dringenberg HC, Rubenstein ML, Solty $\mathrm{H}$, Tomaszek S, Bruce A Electroencephalographic activation by tacrine, deprenyl, and quipazine: cholinergic vs. non-cholinergic contributions. Eur J Pharmacol 2002;447(1):43-50.

Ebert U, Kirch W. Scopolamine model of dementia: electroencephalogram findings and cognitive performance. Eur J Clin Invest 1998;28(11):944-9 [review].

Fernandez A, Arrazola J, Maestu F, Amo C, Gil-Gregorio P, Wienbruch C, et al. Correlations of hippocampal atrophy and focal low-frequency magnetic activity in Alzheimer disease: volumetric MR imaging-magnetoencephalographic study. Am J Neuroradiol 2003;24(3):481-7.

Fioravanti M, Nacca D, Buckley AE, Ferrario E, Varetto O, Mogni P, et al. The Italian version of the Alzheimer's disease assessment scale (ADAS): psychometric and normative characteristics from a normal aged population. Arch Gerontol Geriatr 1994;19(1):21-30.

Folstein MF, Folstein SE, McHugh PR. 'Mini Mental State': a practical method for grading the cognitive state of patients for clinician. J Psychiat Res 1975;12:189-98.

Frisoni GB, Beltramello A, Binetti G, Bianchetti A, Weiss C, Scuratti A, et al. Computed tomography in the detection of the vascular component in dementia. Gerontology 1995;41(2):121-8.

Galluzzi S, Sheu CF, Zanetti O, Frisoni GB. Distinctive clinical features of mild cognitive impairment with subcortical cerebrovascular disease. Dement Geriatr Cogn Disord 2005;19(4):196-203.

Geula C, Mesulam MM. Cortical cholinerigc fibers in aging and Alzheimer's disease: a morphometric study. Neuroscience 1989;33:469-81.

Geula C, Mesulam MM. Systematic regional variations in the loss of cortical cholinergic fibers in Alzheimer's disease. Cereb Cortex 1996;6:165-77.

Geula C, Mesulam MM. Cholinergic system in Alzheimer's disease. In: Terry RD et al., editors. Alzheimer disease. 2nd ed. Lippincot, Philadelphia, PA: Williams and Wilkins; 1999. p. 69-292.

Gloor P, Ball G, Schaul N. Brain lesions that produce delta waves in the EEG. Neurology 1977;27(4):326-33.

Harmony T, Fernandez-Bouzas A, Marosi E, Fernandez T, Bernal J, Rodriguez M, et al. Correlation between computed tomography and voltage and current source density spectral EEG parameters in patients with brain lesions. Electroencephalogr Clin Neurophysiol 1993;87(4):196-205.

Harrison JE. Measuring cognitive change in Alzheimer's disease clinical drug trials. J Nutr Health Aging 2007;11(4):327-9 [review]

Helkala EL, Hanninen T, Hallikainen M, Kononen M, Laakso MP, Hartikainen P, et al. Slow-wave activity in the spectral analysis of the electroencephalogram and volumes of hippocampus in subgroups of Alzheimer's disease patients. Behav Neurosci 1996;110(6):1235-43.

Henderson AS, Jorm AF, Christensen H, Jacomb PA, Korten AE. Aspirin, antiinflammatory drugs and risk of dementia. Int J Geriatr Psychiatry 1997;12(9):926-30

Hensel S, Rockstroh B, Berg P, Elbert T, Schonle PW. Left-hemispheric abnormal EEG activity in relation to impairment and recovery in aphasic patients. Psychophysiology 2004;41(3):394-400.

Holschneider DP, Waite JJ, Leuchter AF, Walton NY, Scremin OU. Changes in electrocortical power and coherence in response to the selective cholinergic immunotoxin 192 IgG-saporin. Exp Brain Res 1999;126(2):270-80.

Huang C, Wahlund LO, Dierks T, Julin P, Winblad B, Jelic V. Discrimination of Alzheimer's disease and mild cognitive impairment by equivalent EEG sources: a cross-sectional and longitudinal study. Clin Neurophysiol 2000:11:1961-7.

Hughes CP, Berg L, Danziger WL, Coben LA, Martin RL. A new clinical scale for the staging of dementia. Br J Psychiatry 1982;140:566-72.

In 't Veld BA, Launer LJ, Hoes AW, Ott A, Hofman A, Breteler MM, et al. NSAIDs and incident Alzheimer's disease. The Rotterdam study. Neurobiol Aging 1998;19:607-11.

Jelic V, Shigeta M, Julin P. Quantitative electroencephalography power and coherence in Alzheimer's disease and mild cognitive impairment. Dementia 1996; 7:314-23.

Jelic V, Johansson SE, Almkvist O, Shigeta M, Julin P, Nordberg A, et al. Quantitative electroencephalography in mild cognitive impairment: longitudinal changes and possible prediction of Alzheimer's disease. Neurobiol Aging 2000;21:533-40.

Jeong J. EEG dynamics in patients with Alzheimer's disease. Clin Neurophysiol 2004;115(7):1490-505

Katz S. Assessing self-maintenance: activities of daily living, mobility, and instrumental activities of daily living. J Am Geriatr Soc 1983;31:721-7.

Katz IR. Diagnosis and treatment of depression in patients with Alzheimer's disease and other dementias. J Clin Psychiatry 1998;59(suppl 9):38-44.

Klimesch W. Memory processes, brain oscillations and EEG synchronization. Int J Psychophysiol 1996;24(1-2):61-100.

Klimesch W. EEG alpha and theta oscillations reflect cognitive and memory performance: a review and analysis. Brain Res Rev 1999;29:169-95.

Klimesch W, Doppelmayr M, Pachinger T, Russegger $H$. Event-related desynchronization in the alpha band and the processing of semantic information. Brain Res Cogn Brain Res 1997;6(2):83-94.

Klimesch W, Doppelmayr M, Russegger H, Pachinger T, Schwaiger J. Induced alpha band power changes in the human EEG and attention. Neurosci Lett 1998;244(2):73-6.

Kobayashi Y, Tadashi I. Sensory-motor gating and cognitive control by the brainstem cholinergic system. Neural Networks 2002:731-41.

Kogan EA, Korczyn AD, Virchowsy RG, Klimovizky SSh, Treves TA, Neufeld MY. EEC changes during long-term treatment with donepezil in Alzheimer's disease patients. J Neural Transm 2001;108:1167-73.

Kolev V, Yordanova J, Basar-Eroglu C, Basar E. Age effects on visual EEC responses reveal distinct frontal alpha networks. Clin Neurophysiol 2002;113(6):901-10.

Laufer I, Pratt H. Evoked potentials to auditory movement sensation in duplex perception. Clin Neurophysiol 2003;114(7):1316-31. 
Lawton MP, Brodie EM. Assessment of older people: self maintaining and instrumental activity of daily living. J Gerontol 1969;9:179-86.

Leuchter AF, Cook IA, Newton TF, Dunkin J, Walter DO, Rosenberg Tompson S, et al. Regional differences in brain electrical activity in dementia: use of spectral power and spectral ratio measures. Electroenceph Clin Neurophysiol 1993;87:385-93.

Lim GP, Yang F, Chu T, Chen P, Beech W, Teter B, et al. Ibuprofen suppresses plaque pathology and inflammation in a mouse model for Alzheimer's disease. J Neurosci 2000;20:5709-14.

Mash DC, Flynn DD, Potter LT. Loss of M2 muscarine receptors in the cerebral cortex in Alzheimer's disease and experimental cholinergic denervation. Science 1985;228(4703):1115-7. 31

Maurer K, Dierks T. Functional imaging procedures in dementias: mapping of EEG and evoked potentials. Acta Neurol Scand Suppl 1992;139:40-6.

McKeith IG, Perry EK, Perry RH. Report of the second dementia with Lewy body international workshop: diagnosis and treatment. Consortiumon dementia with Lewy bodies. Neurology 1999;53:902-25.

McKhann G, Drachman D, Folstein M, Katzman R, Price D, Stadlan EM. Clinical diagnosis of Alzheimer's disease: report of the NINCDS-ADRDA Work Group under the auspices of Department of Health and Human Services Task Force on Alzheimer's disease. Neurology 1984;34:939-44.

Mesulam M, Shaw P, Mash D, Weintraub S. Cholinergic nucleus basalis tauopathy emerges early in the aging-MCI-AD continuum. Ann Neurol 2004:55(6):815-28.

Moretti DV, Babiloni F, Carducci F, Cincotti F, Remondini E, Rossini PM, et al. Computerized processing of EEG-EOG-EMG artifacts for multicentirc studies in EEG oscillations and event-related potentials. Int J Pshycophysiol 2003;47(3):199-216.

Mulert C, Gallinat J, Pascual-Marqui R, Dorn H, Frick K, Schlattmann P, et al. Reduced event-related current density in the anterior cingulate cortex in schizophrenia. Neuroimage 2001;13(4):589-600.

Murri L, Gori S, Massetani R, Bonanni E, Marcella F, Milani S. Evaluation of acute ischemic stroke using quantitative EEG: a comparison with conventional EEG and CT scan. Neurophysiol Clin 1998;28(3):249-57.

Nobili F, Taddei G, Vitali P, Bazzano L, Catsafados E, Mariani G, et al. Relationships between 99m Tc-HMPAO ceraspect and quantitative EEG observations in Alzheimer's disease. Arch Gerontol Geriatr 1998;6:363-8.

Nuwer MR. Quantitative EEG. I : techniques and problems of frequency analysis and topographic mapping. J Clin Neurophysiol 1998;5:1-43.

Onofrj M, Thomas A, Iacono D, Luciano AL, Di Iorio A. The effects of a cholinesterase inhibitor are prominent in patients with fluctuating cognition: a part 3 study of the main mechanism of cholinesterase inhibitors in dementia. Clin Neuropharmacol 2003;26:239-51.

Pascual-Marqui RD, Michel CM. LORETA (low resolution brain electromagnetic tomography): new authentic 3D functional images of the brain. ISBET Newsletter ISSN 1994;5:4-8.

Pascual-Marqui RD, Lehmann D, Koenig T, Kochi K, Merlo MC, Hell D, et al. Low resolution brain electromagnetic tomography (LORETA) functional imaging in acute, neuroleptic-naive, first-episode, productive schizophrenia. Psychiatry Res 1999;90(3):169-79.

Pascual-Marqui RD, Esslen M, Kochi K, Lehmann D. Functional imaging with low resolution brain electromagnetic tomography (LORETA): a review. Methods Find Exp Clin Pharmacol 2002;24:91-5.

Phillips C, Rugg MD, Friston KJ. Systemic regularization of linear inverse solutions of the EEG source localization problem. Neuroimage 2002;17:287-301.

Ponomareva NV, Selesneva ND, Jarikov GA. EEG alterations in subjects at high familial risk for Alzheimer's disease. Neuropsychobiology 2003;48(3):152-9.

Prichep et al., 1994 Prichep LS, John ER, Ferris SH, Reisberg B, Almas M, Alper K, et al. Quantitative EEG correlates of cognitive deterioration in the elderly. Neurobiol Aging 1994;15(1):85-90Prichep et al., 1994 Prichep LS, John ER, Ferris SH, Reisberg B, Almas $M$, et al. Quantitative EEG correlates of cognitive deterioration in the elderly. Neurobiol Aging 1994;15(1):85-90 [Erratum in: Neurobiol Aging 1994;15(3):391]

Pucci E, Cacchiò G, Angeloni R, Belardinelli N, Nolfe G, Signorino M, et al. EEG spectral analysis in Alzheimer's disease and different degenerative dementias. Arch Gereontol Geriat 1997;26:283-97.

Ray PG, Jackson WJ. Lesions of nucleus basalis alter ChAT activity and EEG in rat frontal neocortex. Electroencephalogr Clin Neurophysiol 1991;79(1):62-8.

Reeves RR, Struve FA, Patrick G. The effects of donepezil on quantitative EEG in patients with Alzheimer's disease. Clin Electroencephalogr 2002;33(2):93-6.

Reines SA, Block GA, Morris JC, Liu G, Nessly ML, Lines CR, et al. Rofecoxib: no effect on Alzheimer's disease in a 1-year, randomized, blinded, controlled study. Neurology 2004;62(1):66-71.

Rodriguez G, Nobili F, Rocca G, DeCarli F, Gianelli MV, Rosadini G. Quantitative electroencephalography and regional cerebral blood flow: discriminant analysis between Alzheimer's patients and healthy controls. Dement Geriatr Cogn Disord 1998:9:238-74.

Rodriguez G, Copello F, Nobili F, Vitali P, Perego G, Nobili F. EEG spectral profile to stage Alzheimer's disease. Clin Neurophysiol 1999;110:1831-7.

Rodriguez G, Vitali P, De Leo C, De Carli F, Girtler N, Nobili F. Quantitative EEC changes in Alzheimer patients during long-term donepezil therapy. Neuropsychobiology 2002;46:49-56.

Rogers J, Kirby LC, Hempelman SR, Berry DL, McGeer PL, Kaszniak AW, et al. Clinical trial of indomethacin in Alzheimer's disease. Neurology 1993;43(8):1609-11.

Román GC, Tatemichi TK, Erkinjuntti T, Cummings JL, Masdeu JC, Garcia JH, et al Vascular dementia: diagnostic criteria for research studies. Report of the NINDS-AIREN international workshop. Neurology 1993;43(2):250-60.

Rossini PM, Rossi S, Babiloni C, Polich J. Clinical neurophysiology of aging brain: from normal aging to neurodegeneration. Prog Neurobiol 2007;83(6):375-400 [Epub 2007 August 8; Review December].

Rozzini L, Vicini Chilovi B, Bertoletti E, Conti M, Delrio I, Trabucchi M, et al. The importance of Alzheimer disease assessment scale-cognitive part in predicting progress for amnestic mild cognitive impairment to Alzheimer disease. J Geriatr Psychiatry Neurol 2008;21(4):261-7.

Sarter M, Bruno JP. Mild cognitive impairment and the cholinergic hypothesis: a very different take on recent data. Ann Neurol 2002;52(3):384-5.

Scharf S, Mander A, Ugoni A, Vajda F, Christophidis N. A double-blind, placebocontrolled trial of diclofenac/misoprostol in Alzheimer's disease. Neurology 1999;53(1):197-201

Schreiter-Gasser U, Gasser T, Ziegler P. Quantitative EEG analysis in early onset Alzheimer's disease: a controlled study. Electroencephalogr Clin Neurophysiol 1993;86(1):15-22.

Sloan EP, Fenton GW, Kennedy NSJ, MacLennan JM. Electroencephalography and single photon emission computed tomography in dementia: a comparative study. Psychol Med 1995;25:631-8.

Soininen H, West C, Robbins J, Niculescu L. Long-term efficacy and safety of celecoxib in Alzheimer's disease. Dement Geriatr Cogn Disord 2007;23(1):8-21.

Speilberger CD. Manual for the state-trait anxiety inventory (Form Y-1). Palo Alto, CA: Consulting Psychologists Press; 1983.

Steriade M. Neuronal substrates of sleep and epilepsy. Cambridge (UK): Cambridge University Press; 2003. p. 522.

Steriade M, Amzica F, Contreras D. Synchronization of fast $(30-40 \mathrm{~Hz})$ spontaneous cortical rhythms during brain activation. J Neurosci 1996;16:392-417.

Stewart GR, Frederickson CJ, Howell GA, Gage FH. Cholinergic denervation-induced increase of chelatable zinc in mossy-fiber region of the hippocampal formation. Brain Res 1984;290(1):43-51.

Stewart WF, Kawas C, Corrada M, Metter EJ. Risk of Alzheimer's disease and duration of NSAID use. Neurology 1997;48(3):626-32.

Szelies B, Grond M, Herholz K, Kessler J, Wullen T, Heiss WD. Quantitative EEC mapping and PET in Alzheimer's disease. J Neurol Sci 1992;110:46-56.

Talairach J, Tournoux P. Co-planar stereotaxic atlas of the human brain. Stuttgart: Thieme; 1988.

Tanaka Y, Hanyu H, Sakurai H, Takasaki M, Abe K. Atrophy of the substantia innominata on magnetic resonance imaging predicts response to donepezil treatment in Alzheimer's disease patients. Dement Geriatr Cogn Disord 2003;16:119-25.

The Lund and Manchester Groups. Clinical and neuropathological criteria for frontotemporal dementia. J Neurol Neurosurg Psychiatry 1994;57:416-18.

Weggen S, Eriksen JL, Das P, Sagi SA, Wang R, Pietrzik CU, et al. A subset of NSAIDs lower amyloidogenic Abeta42 independently of cyclooxygenase activity. Nature 2001;414(6860):212-6

Wesnes KA. Assessing change in cognitive function in dementia: the relative utilities of the Alzheimer's disease assessment scale-cognitive subscale and the cognitive drug research system. Neurodegener Dis 2008;5(3-4):261-3.

Wolf H, Jelic V, Gertz HJ, Nordberg A, Julin P, Wahlund LO. A critical discussion of the role of neuroimaging in mild cognitive impairment. Acta Neurol Scand 2003;107(Suppl. 179):52-76.

Yao D, He B. A self-coherence enhancement algorithm and its application to enhancing three-dimensional source estimation from EEGs. Ann Biomed Eng 2001;29:1019-27.

Yesavage JA, Brink TL, Rose TL, Lum O, Huang V, Adey M, et al. Development and validation of a geriatric depression screening scale: a preliminary report. Psychiatr Res 1982;17(1):37-49. 83.

Zandi PP, Anthony JC, Hayden KM, Mehta K, Mayer L, Breitner JC. Reduced incidence of AD with NSAID but not $\mathrm{H} 2$ receptor antagonists: the Cache County study Neurology 2002;59(6):880-6.

Zanetti O, Bonomini C, Pasqualetti P, Milazzo D, Paulon L, Dal Forno, et al. Effects of ibuprofen on Alzheimer's disease cognitive progression: a randomized controlled trial. Alzheimer's Dementia 2006;2:P2407. S366. 